\title{
Novel Plantar Surface Design of a Hinged Ankle Foot Orthosis (HAFO) Manufactured by 3D Printing
}

\author{
Mariana Ribeiro Volpini Lana ${ }^{1}$, Paulo Henrique Rodrigues Guilherme Reis ${ }^{1,2}$, Anderson Horta ${ }^{1}$, Joana \\ Pimenta Maia'; Mariana Rodrigues Carvalho de Aquino', Juan Carlos Campos Rubio ${ }^{2}$ \\ ${ }^{1}$ AMR - Associação Mineira de Reabilitação \\ Professor Otávio Coelho de Guimarães Street, 111 - Mangabeiras, Belo Horizonte, MG, Brazil \\ marianavolpini@amr.org.br; andersonhorta@gmail.com; joanapimentato@gmail.com; marircaquino@gmail.com \\ ${ }^{2}$ UFMG - Universidade Federal de Minas Gerais \\ Antônio Carlos Avenue, 6627 - Pampulha, Belo Horizonte, MG, Brazil \\ paulogsk@gmail.com; juan@ufmg.br
}

\begin{abstract}
Ankle foot orthosis manufactured by 3D printing have several benefits in terms of the manufacturing process, such as the diversity of designs and precision of manufacture. However, for the 3D printed orthosis to be functional, it is necessary to observe its mechanical behavior in relation to the forces acting during gait. It is common to observe high stiffness in orthoses manufactured by $3 \mathrm{D}$ printing during the foot roll phase, which can interfere with the performance of functional mobility. This study proposes new geometry in the plantar region of the orthosis, based on data from computer simulations, in order to provide its flexibility during gait, helping to improve the performance of this functional activity. The results showed that the new surface deformed $465 \%$ more (30.01 mm) compared to the traditional surface $(6.45 \mathrm{~mm})$.
\end{abstract}

Keywords: Orthosis; 3D Print; Finite Elements Analysis; Gait.

\section{Introduction}

Ankle-Foot Orthosis (AFO) is a complementary resource in the rehabilitation of individuals with neuromotor disorders used to prevent muscle shortening and bone deformities and to promote biomechanical alignment and improve gait functionality [1,2]; Hinged AFO (HAFO) can be used in different gait patterns such as equine or drop foot [3,4] because it stabilizes the ankle, limiting the plantar flexion movement, without restricting dorsal flexion [5].

Additive Manufacturing (AM), also called 3D printing, has been increasingly considered a promising manufacturing technique for rehabilitation devices due to the possibility of making products with complex and varied shapes quickly and accurately $[3,6]$.

Although it has several advantages, the manufacture of the HAFO by AM must guarantee flexibility so that the functional benefits of the foot roll during the step are maintained. It is common to see in AFOs made by AM high stiffness, especially in the plantar region, which can interfere with gait performance. In this way, new geometric shapes in devices manufactured by AM must be developed to enable, in the same device, areas that present greater rigidity, providing biomechanical alignment and the containment of the desired range of motion, and areas of greater flexibility, enabling kinematics adequate gait [7].

The aim of this study was to improve the HAFO manufactured by the AM process by modifying its plantar surface. For this purpose, simulations by Finite Element Analysis (FEA) were used.

\section{Method}

This is a methodological study with application of numerical simulation by finite elements. The mechanical properties of HAFO's manufacturing material were analyzed by 3D printing, the modeling of the new plantar region of this device and, finally, the influence of these changes on its stiffness and stress distribution. The results obtained by AEF in the traditional model, without modification in the plantar region, and in the new model were then compared. 


\subsection{Mechanical Properties}

To assess the mechanical properties of the orthosis, a previous characterization of the material to be used in the manufacture of HAFO by AM was performed. Table 1 shows the main properties estimated in tests performed on specimens considering different printing directions. The 3D printing technique used was Selective Laser Sintering (SLS), using a 3D System printer, model ProX 500.

Table 1: Mechanical properties of material.

\begin{tabular}{|l|c|}
\hline \multicolumn{1}{|c|}{ Property } & Module \\
\hline Modulus of Elasticity (GPa) & 1.4 \\
\hline Flow Resistance (Mpa) & 19.2 \\
\hline Tensile Strength (N/m $\left.{ }^{2}\right)$ & 40.7 \\
\hline
\end{tabular}

\subsection{Modeling of the Plantar Region}

to assist in the flexibility of the HAFO plantar region, surface modifications were made from the removal of material by geometric patterns. This modification allowed a decrease in the resistance of the orthosis at the moment of flexion. The new model of the plantar region used from the removal of material can be seen in Figure 01.

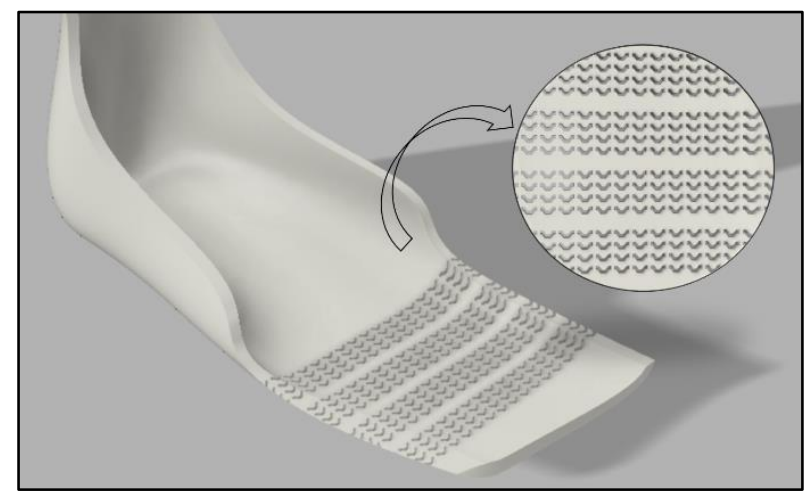

Fig. 1: New plantar region of the orthosis.

\subsection{Finite Element Analysis}

In order to assess the influence of the change in the HAFO plantar region in relation to flexibility during gait, computational simulation of static forces by FEA was performed. The analysis was performed considering the gait kinematics of an adult of $50 \mathrm{~kg}$, with $500 \mathrm{~N}$ forces acting on the forefoot resulting from the phase of the terminal support of the gait. The dimensions of the plantar region of the orthosis as well as the region of force application are described in Figure 2. 

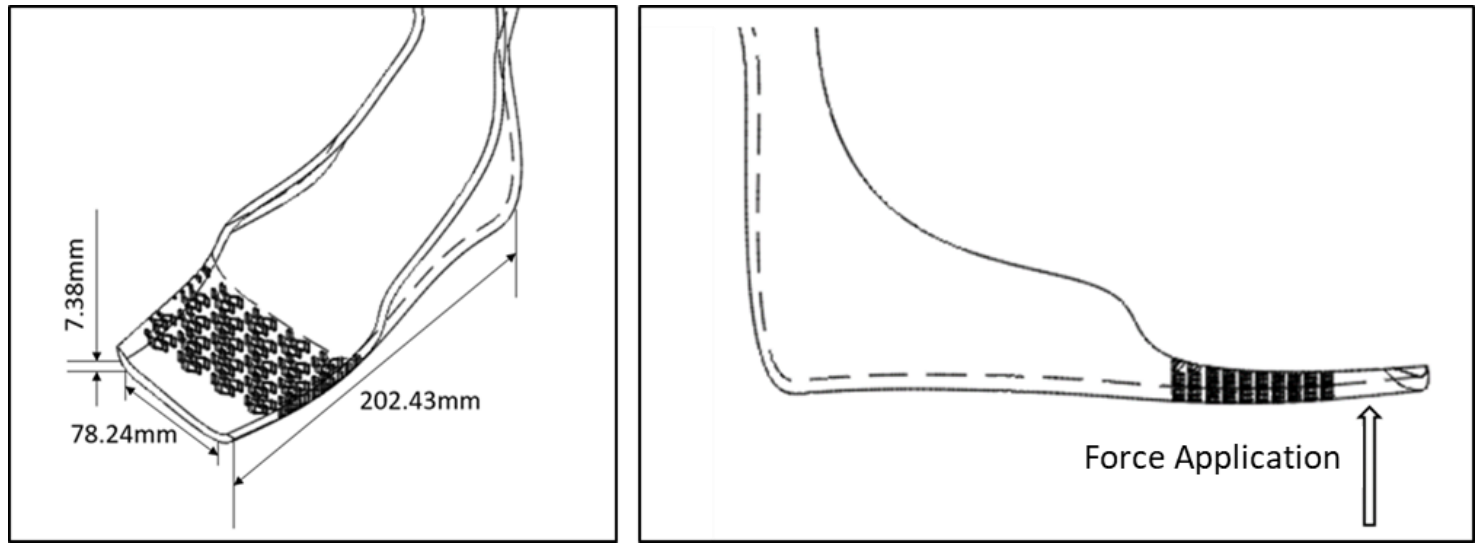

Fig. 2: Dimensions of the plantar region of the orthosis and region of force application for FEA.

\section{Results and discussion}

It was observed that the new model of the forefoot region showed $465 \%$ more significant plastic deformation when compared to the percentage displacement observed in the traditional model of the plantar region of the orthosis. The displacement observed in the new model was $30.01 \mathrm{~mm}$, while the displacement observed in the traditional model, with no change in the plantar region, was $6.45 \mathrm{~mm}$. Figure 3 shows the color map of the verified percentage shifts.

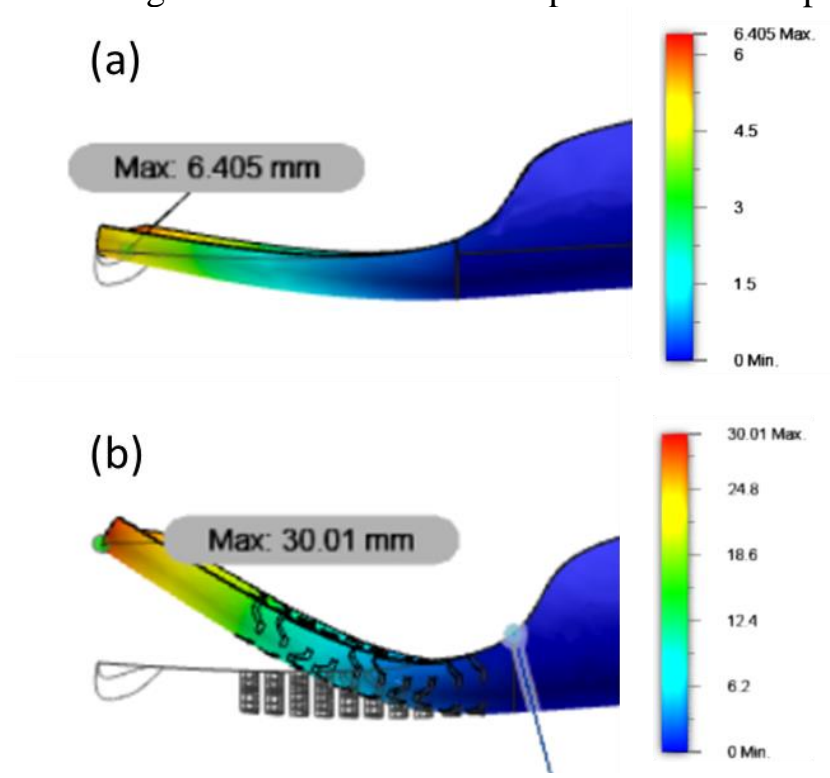

Fig. 3: Percentage shift of study models. (a) displacement of the region with traditional plantar surface (b) displacement of the region with modified plantar surface.

\section{Conclusion}

The results of this study show that the development of material removal patterns in specific regions of the orthoses manufactured by AM provides a significant increase in the flexibility of HAFO, which should favor the best development of gait, due to the possibility of the foot rolling. Further studies, with clinical tests of this new HAFO planar surface, should be carried out to determine its effects on gait functionality. 


\section{Acknowledgements}

All financial resources necessary for the execution of the project were acquired through the Ministry of Health through the PRONAS / PCD program, with SIPAR number: 25000163653 / 2014-33

\section{References}

[1] Deberg L., Taheri A., Andani M., Hosseinipour M., Elahinia M. An SMA Passive ankle foot orthosis: Design, modeling, and experimental evaluation. Smart Materials Research. 2014;

[2] Kelly M., Spires M. C., Restrepo J. A., Orthotic and prosthetic prescriptions for today and tomorrow. Physical medicine and rehabilitation clinics of North America. V. 18. 2007, p.785-858.

[3] Faustini M. C., Neptune R. R., R. Crawford H., Stanhope S. J. Manufacture of passive dynamic ankle-foot orthoses using selective laser sintering. IEEE Trans Biomed Eng. 2008

[4] Salles S., Gyi D. E.: An evaluation of personalised insoles developed using additive manufacturing. J Sports Sci. 2013.

[5] Syngellakis S., Arnold M.A. Modelling considerations in finite element analyses of ankle foot orthoses. WIT Transactions on Ecology and The Environment, vol. 160, 2012.

[6] Schrank S., Hitch L., Moore K. Wallace, R., Stanhope S. J.: Assessment of a virtual functional prototyping process for the rapid manufacture of passive-dynamic ankle-foot orthoses. J Biomech Eng. 2013

[7] Jamshidi N., Hanife M., Rostami M., Najrian S., Menhaj M. B. Saadatnia M., Salami F.: Modelling the interaction of ankle-foot orthosis and foot by finite element methods to design an optimized sole in steppage gait. Journal of Medical Engineering \& Technology, Vol. 34, No. 2, February 2010, pp. 116-123. 